\title{
Análise da obra Kurze Schatten ll de Brian Ferneyhough
}

\author{
Felipe Merker Castellani (Faculdade Santa Marcelina, São Paulo) \\ felipemerkercastellani@yahoo.com.br
}

Resumo. Análise dos três primeiros movimentos da obra Kurze Schatten // para violão solo de Brian Ferneyhough, na qual são discutidos aspectos de sua técnica composicional, além de conceitos importantes na obra do compositor. Palavras-chave: análise musical, composição, música do século XX, Brian Ferneyhough, Kurze Schatten II.

\section{Analysis of Brian Ferneyhough's Kurze Schatten II}

Abstract. Analysis of the first three movements of Brian Ferneyhough's Kurze Schatten II for solo guitar. It discusses compositional techniques and strategies used by the composer. It also includes concepts and structures typical of the composer's musical language.

Keywords: musical analysis, composition, twentieth-century music, Brian Ferneyhough, Kurze Schatten II.

A obra Kurze Schatten II para violão solo em sete movimentos foi composta por Brian Ferneyhough entre 1983-1989, atendendo ao pedido do violonista Magnus Andersson, a quem foi dedicada. Sua estréia foi realizada no início do ano de 1990, em Genebra, pelo próprio Magnus Andersson. Os três primeiros movimentos que terão sua análise apresentada abaixo foram compostos entre 1983-1984, e apresentam como seu critério de composição um ponto específico.

Dividi este artigo, que apresenta o resultado parcial de pesquisa realizada com bolsa concedida pela FAPESP, da seguinte forma: Primeira parte, sobre o compositor, consiste em uma pequena biografia do compositor. Segunda parte, sobre a obra, apresenta algumas informações sobre a organização geral da peça. Terceira parte, análise. Quarta parte, considerações finais.

\section{1 - Sobre Brian Ferneyhough}

0 compositor Brian Ferneyhough nasceu em Coventry, Inglaterra, em 1943. Sua formação inicial foi como instrumentista, realizando seus primeiros estudos formais na Birmingham School of Music. Após este período ingressou na Royal Academy of Music em Londres, na qual teve aulas de composição com Lennox Berkeley. Segundo Ferneyhough, Berkeley não sabia exatamente o que fazer com suas composições, e em vez de aulas de composição, ficavam discutindo temas relacionados a literatura, poesia e filosofia.

Durante o curso na Royal Academy of Music, o compositor tornou-se diretor do Academy's New Music Club, e fundou e regeu o Arradon Ensemble, especializado em música contemporânea. É deste período que datam as primeiras obras do seu catálogo de composições: Sonatina (1963), para três clarinetes e fagote, Quatro Miniaturas(1965), para flauta e piano e Coloratura (1966), para oboé e piano.

A composição destas primeiras obras foi influenciada pelos estudos pessoais dos compositores Webern, Boulez e Stockhausen, podendo ainda destacar dentre produção destes, a primeira fase de Webern (do 0p.1 ao 0p. 11), as Structures de Boulez e os Klavierstüken de Stockhausen. Porém Ferneyhough só iniciou realmente seus estudos de composição em 1968, em Amsterdã, quando começou a ter aulas com Ton de Leeuw, e mais tarde, em 1969, com Klaus Huber, na Basiléia.

Podemos notar uma maior complexidade em sua escrita instrumental durante este período, onde "mergulha" o intérprete em uma crescente e alternada troca de modos ataque instrumentais, sendo necessário um total envolvimento físico e mental do mesmo, como é o caso das obras: Cassandra's dream song (1970) e Time and Motion Study I (1971-77).

No ano de 1973, o compositor passou a atuar como professor de composição em Freiburg. Em 1976, foi professor convidado no festival de Darmstad, e, a partir de 1987, foi professor de composição da University of California em San Diego.

Uma característica a ser destacada na produção que segue, é a presença de aspectos extra-musicais, sendo muitas obras inspiradas em pinturas, textos filosóficos, como $L a$ 
terre este un homme (1976-1979), para orquestra, que foi inspirada em uma pintura de Roberto Matta e também a obra Lemma-Icon-Epigram (1981), para piano solo, que possuiu elementos da poesia de Andrea Alciato.

Posteriormente apresentam-se algumas composições auxiliadas por computador, entre elas BoneAlphabeth(1991), para percussão solo, e Trio (1995), para trio de cordas.

Dentre sua produção mais recente podemos destacar as seguintes obras: a ópera Shadowtime (que teve sua estréia em maio de 2004), baseada na vida e obra do filósofo Walter Benjamin, o Fifth String Quartet (que teve sua estréia em 2005), e a peça orquestral Plötzlichkeit (que teve sua estréia no Donaueschingen Music Festival em outubro de 2006).

Atualmente, Ferneyhough atua junto à Stanford University (desde 2000), em diversos festivais, com o de Milão, Darmstad (desde 1976) e o da Foundation Royaumont em Paris, e também como pesquisador, junto ao IRCAM, também em Paris.

\section{2 - Sobre Kurze Schatten II}

Ao tomar contato com alguns procedimentos composicionais já catalogados dentro da obra de Brian Ferneyhough, me deparei com a impressionante dificuldade de analisar suas obras, principalmente quando não é possivel o acesso a seus esboços e/ou manuscritos. Posso citar dois fatores com que esta dificuldade está relacionada: um deles é a grande "espessura perspectiva" com que o compositor trabalha os processos derivados do pensamento serial, ou seja, ele se utiliza de diversas acumulações, sobreposições e filtragens, quase sempre paralelas e muitas vezes simultâneas, tanto no que diz respeito aos procedimentos com relação às alturas como também ao ritmo, e que vão sendo recombinados e reassociados sem ter algum ponto inicial específico, tornando o trabalho analítico uma tarefa "arqueológica" e muitas vezes quase impossível. 0 outro ponto estaria no fato de que muitas vezes dentro das "restrições"1 (constraints) que Ferneyhough coloca dentro das suas peças podem ocorrer "erros", que modificariam todas as características direcionais de um determinado trecho; esta "abertura" para o imprevisivel caracteriza um dos aspectos de sua chamada escrita informal.

Mais especificamente no caso da obra Kurze Schatten II, me deparei com um "problema" relacionado à notação: a partitura que se encontra disponivel é uma partitura de execução, ou seja, ela não está escrita em "sons reais", e sim na scordatura tradicional do violão; foi então necessário desenvolver uma partitura analítica, com as alturas transpostas para a scordatura referente a cada movimento. 0 compositor entretanto não indica em que corda(s) devem ser executados alguns trechos (em especial no segundo movimento), o que dificultou bastante esta tarefa. Tive então que elaborar uma digitação onde optei pela escolha mais idiomática possível para 0 instrumento, sabendo que essa escolha é pessoal, e que outros violonistas possivelmente encontrariam diferentes soluções técnicas a esse problema.

Por fim, gostaria de concluir este tópico dizendo que esta análise não tentará refazer as diversas etapas de construção da obra, e nem se prender aos detalhes das técnicas e materiais utilizados pelo compositor, pois como foi dito acima, isto é extremamente complexo principalmente por não termos acesso aos manuscritos. Procurei, nesta pesquisa, ater-me aos aspectos mais perceptíveis da partitura final, e através destes, ilustrar alguns dos conceitos e técnicas que facilitarão o entendimento de peculiaridades do pensamento composicional de Brian Ferneyhough.

\section{3 - Análise de Kurze Schatten II}

\begin{abstract}
Sombras curtas
Quando se aproxima o meio-dia, as sombras ainda são apenas as orlas negras e nítidas na base das coisas e estão prontas para, silenciosas, de improviso, se recolher à sua estrutura, ao seu segredo. Então, em sua plenitude densa e encolhida, é chegada a hora de Zaratustra, do pensador no "Lebensmittag" ("Meiodia da Vida"), no "Sommergarten" ("Jardim de Verão"). Pois o conhecimento delineia, como o sol a pino, as coisas com máximo rigor. (BENJAMIN, 2000).
\end{abstract}

Lendo esta descrição, eu imediatamente comecei a planejar uma peça na qual o processo gradualmente se funde com o objeto de maneira que ambos, de um modo hiper-real, se tornem 'eles mesmos' (FERNEYHOUGH, 1998, p.139).2

0 primeiro texto acima, de autoria do filósofo alemão Walter Benjamin serviu de base para a construção da obra Kurze Schatten II. 0 primeiro passo para que a metáfora do compositor pudesse se realizar foi a opção por movimentos extremamente curtos e formalmente concentrados. Esta idéia também vem resolver outra questão, que seria como transferir toda a "força energética" gestual das outras obras de Ferneyhough para o violão, um instrumento que não é tradicionalmente associado a este tipo de linguagem.

A organização geral da peça segue o princípio da suite barroca, ou seja, alterna movimentos lentos e rápidos. Existem três pares de movimentos lentos e rápidos (seis no total), com um movimento final em uma espécie de "fantasia", que visa colocar em um curto espaço de tempo diversas técnicas instrumentais compatíveis à coerência musical.

A ressonância da peça é trabalhada pelo compositor através da escolha de uma sonoridade microtonal que vai se transformando ao longo dos sete movimentos. Para a abertura da peça três cordas são alteradas com uma scordatura microtonal, a primeira (Mi) é rebaixada um quatro de tom, a quinta (Lá) é elevada em três quartos de tom e a sexta (Mi) é elevada em um quarto de tom; a segunda (Si) também é alterada, ela será rebaixada em meio tom, e as demais permanecerão em sua scordatura tradicional (ver Ex.1). 
A cada par de movimentos esta scordatura inicial vai sendo modificada pelo retorno à configuração tradicional do instrumento (Ex.2). A primeira a retornar é a sexta corda, a segunda é a quinta corda e a última a primeira corda, permanecendo apenas a segunda corda diferente do tradicional $\left(\mathrm{Si}_{b}\right)$. 0 resultado perceptivo consiste, em um abandono progressivo da sonoridade peculiar inicial e uma espécie de retomada da ressonância mais familiar do instrumento.

A seguir apresentarei a análise de cada um dos movimentos que são o objeto desta pesquisa.

\section{1 - 0 Primeiro movimento de Kurze Schatten II}

No primeiro movimento, temos o problema de trabalhar em três níveis polifônicos - ou melhor, dois tipos distintos de estruturas polifônicas, uma delas composta por duas camadas independentes de harmônicos naturais (cujos conteúdos absolutos das alturas refletem a scordatura das cordas específicas indicadas), e a outra incorpora o que pode ser denominado como uma polifonia de sucessividade... (FERNEYHOUGH, 1998, p.140).

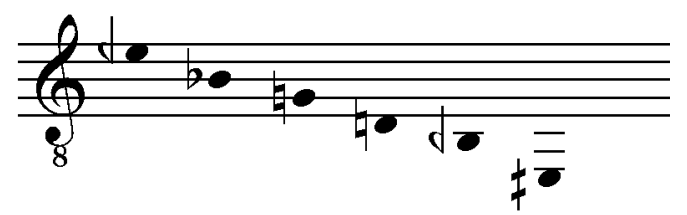

Ex.1- Scordatura inicial de Kurze Schatten II.

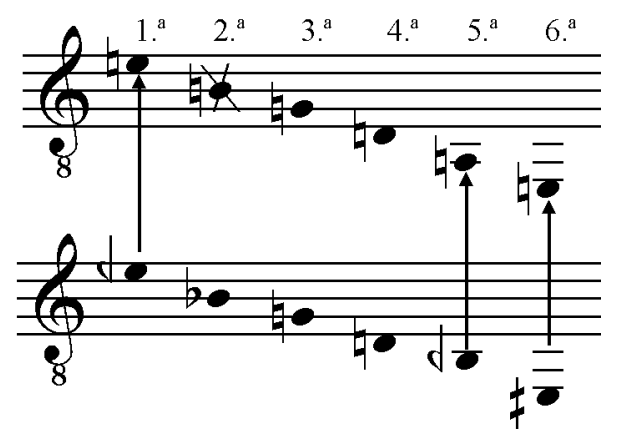

Ex.2- 0 pentagrama superior apresenta a scordatura tradicional do violão, enquanto o inferior mostra a scordatura inicial de Kurze Schatten /l e seus respectivos "retornos" indicados pelas setas.

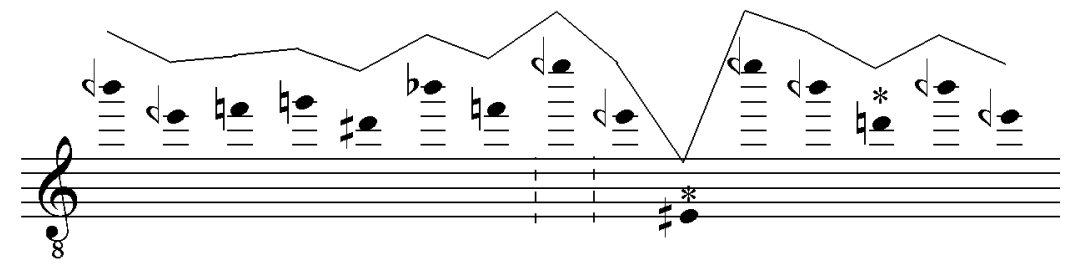

Ex3.- Camada superior de harmônicos naturais com seu respectivo perfil melódico no Mov.l de Kurze Schatten II.

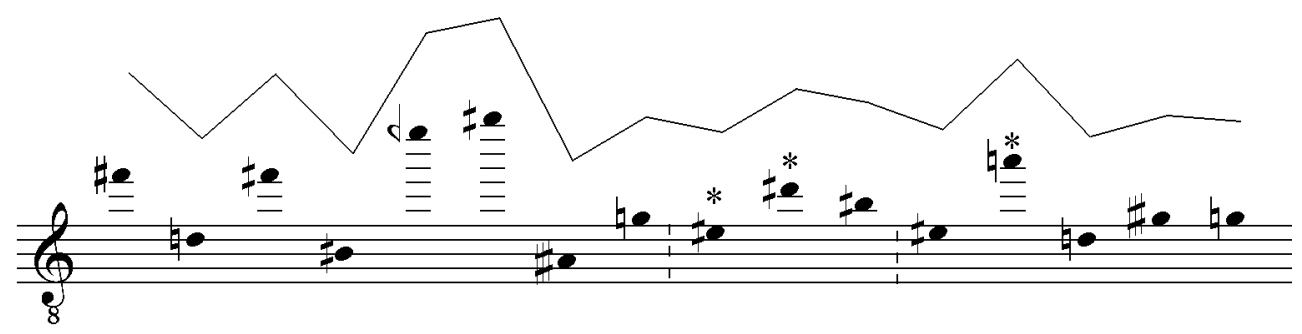

Ex.4- Camada inferior de harmônicos naturais com seu respectivo perfil melódico no Mov.I de Kurze Schatten II. 
Observando separadamente as camadas de harmônicos naturais e seus respectivos perfis melódicos (ver Ex.3 e 4), vemos que existe uma diferente "tendência comportamental" em cada uma delas, caracterizadas pelas distâncias intervalares percorridas, sejam elas pequenas (no caso da camada superior) ou grandes (no caso da camada inferior). Estas tendências, no entanto, são abandonadas no momento do primeiro corte formal da peça, que ocorre no compasso 11 (representado nos exemplos pela primeira linha tracejada). A partir de então observa-se um comportamento mais caótico, sem uma tendência tão evidente.

Na última seção da peça (nos exemplos, representada a partir da segunda linha tracejada), observa-se em ambas as camadas a presença de algumas alturas que não haviam sido apresentadas anteriormente (nos exemplos elas estão assinaladas por um asterisco) e no caso da camada superior existe uma proeminência da nota ${ }^{3} \mathrm{Mi}_{b \downarrow}$.
Ao examinarmos as duas camadas simultaneamente, observamos essa mesma tendência (Ex.5), ou seja, encontramos um primeiro comportamento, que é interrompido no primeiro corte formal da peça.

Apesar de muitas das durações rítmicas indicadas nestas camadas serem apenas hipotéticas, devido à pouca sustentabilidade harmônica inerente ao violão, 0 instrumentista acaba por percorrer distâncias muito grandes com a mão esquerda para que as cordas onde são executados os harmônicos naturais se mantenham livres e não sejam abafadas, o que configura um dos principais desafios técnicos para o instrumentista durante o movimento.

De acordo com o compositor (FERNEYHOUGH, 1998, p.141) no início deste movimento encontramos no pentagrama inferior quatro categorias variáveis de microfiguras (Ex.6) que se sucedem muito rapidamente, e que, ocasionalmente ocorrem sobrepostas umas às outras.

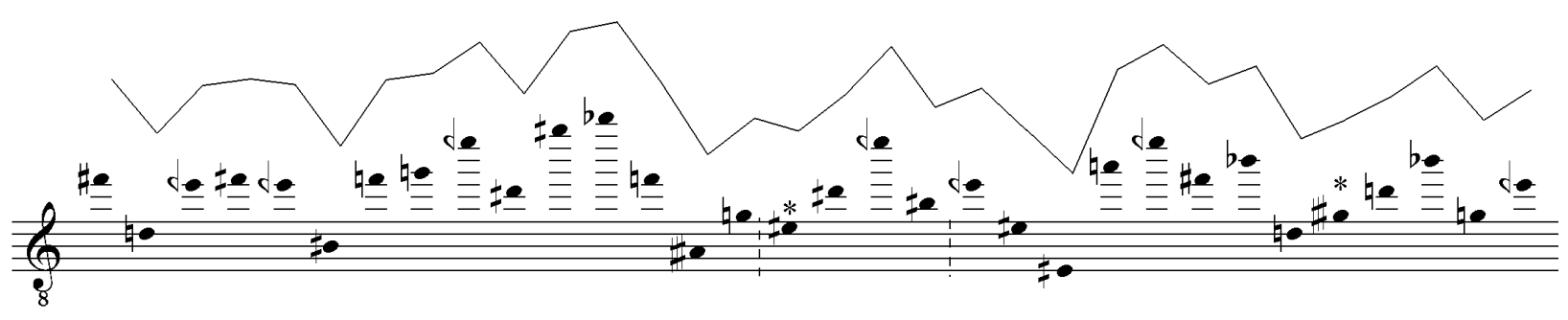

Ex.5- As duas camadas de harmônicos naturais representadas em um único pentagrama com seu respectivo perfil melódico no Mov.I de Kurze Schatten II.
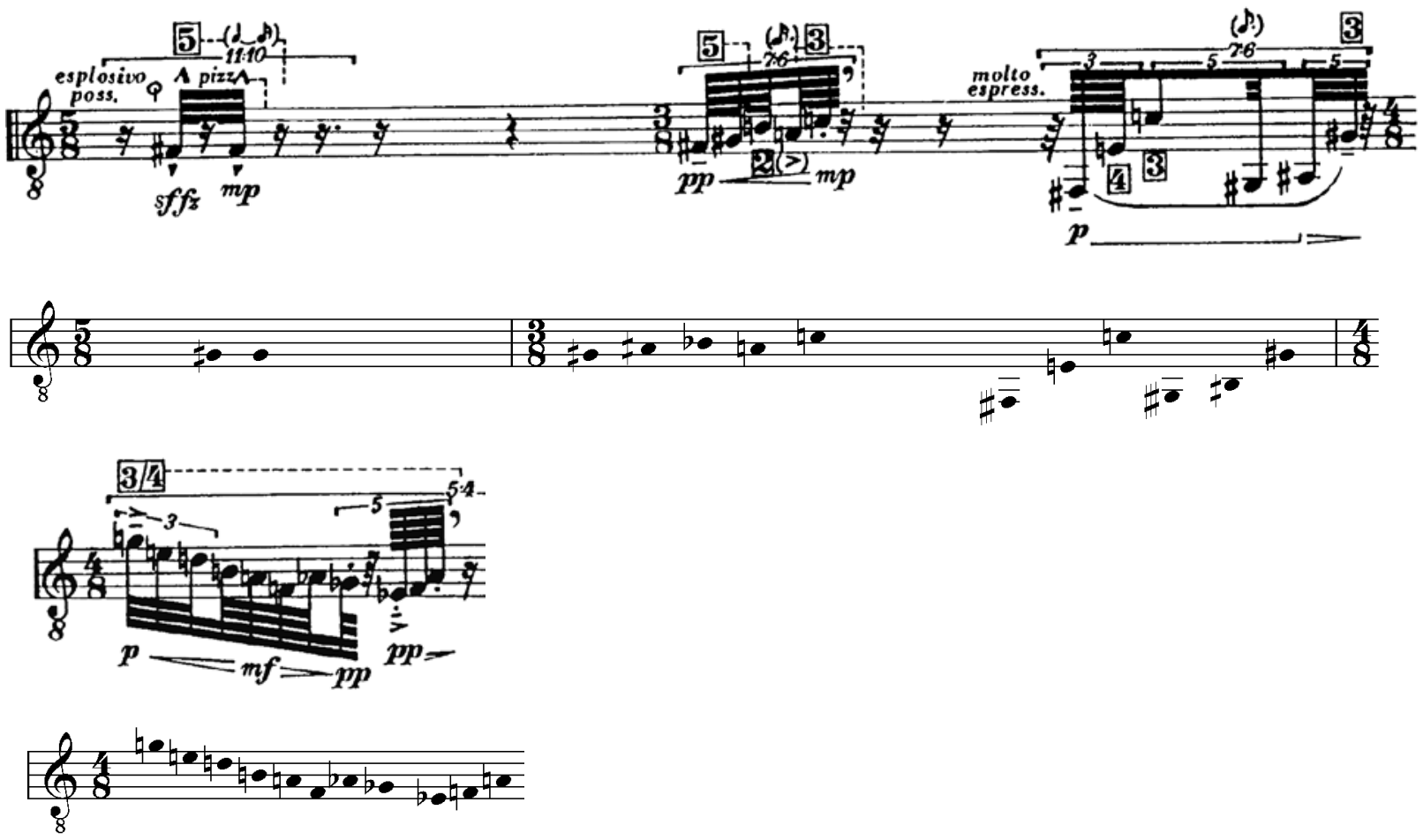

Ex.6- As quatro categorias de micro-figuras apresentadas nos compassos 1, 2 e 3 da partitura original do Mov.I de Kurze Schatten I/ e suas respectivas alturas em sons reais nos pentagramas inferiores. 
Apesar destas figuras variarem muito rapidamente, alterando suas articulações, intensidade, ritmo e perfil melódico (caracterizando a chamada "intensificação figural", que abordaremos detalhadamente adiante), elas também criam uma espécie de "campo de ressonâncias", principalmente pela ênfase de algumas alturas.

Ao observarmos as figuras circuladas no Ex.7, podemos notar que a primeira e a terceira remetem à primeira categoria apresentada no Ex. 6. Apesar de algumas alturas acrescentadas e de variações em intensidade e ritmo, ambas as figuras iniciam com a mesma altura da abertura da peça (a nota Sol ${ }^{\# \uparrow}$ ).
Se compararmos a segunda figura circulada no Ex.7 com a última categoria do início da peça, podemos observar que, apesar das mudanças de intensidade, perfil melódico, articulação, algumas notas que aparecem em outras oitavas e do acréscimo de mais uma altura, assinalada no Ex.8 por um asterisco, temos as mesmas alturas em outra ordenação, com exceção do Sol ${ }^{*}$ e do $\mathrm{Si}_{\mathrm{b}}$ que estavam no acorde posterior da primeira.

Além destes processos relativos às figuras, também podemos perceber, nos acordes, esta idéia de criar um "campo de ressonâncias", através da manutenção de notas comuns aos acordes (Ex.9).
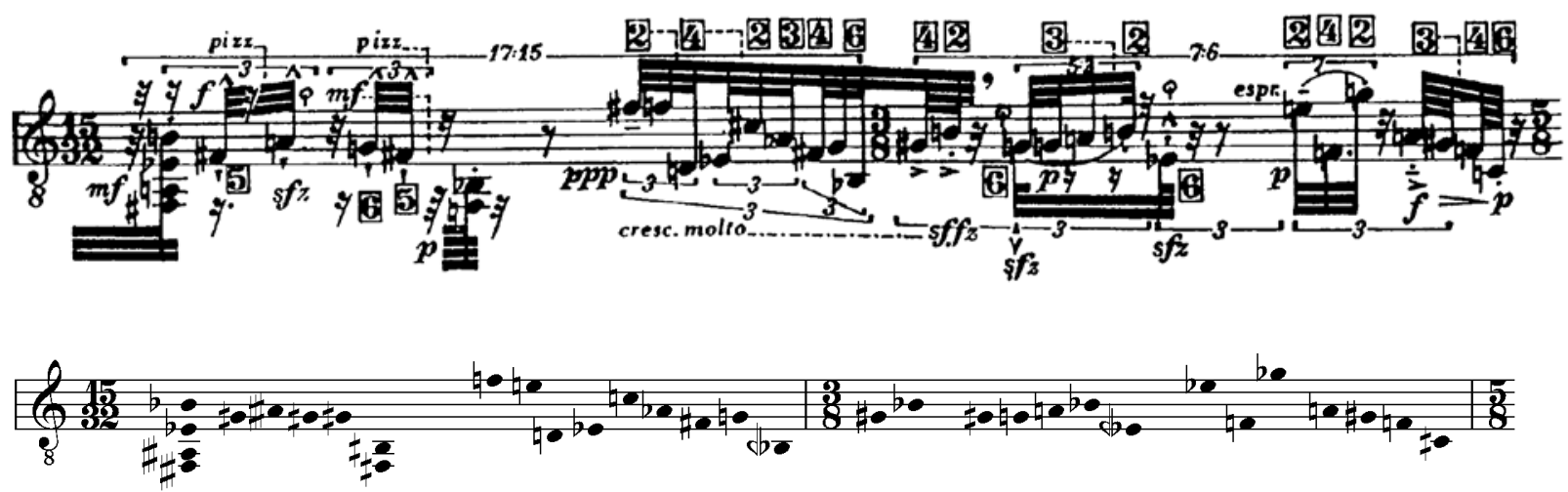

Ex.7- Compassos 5 e 6 da partitura original do Mov.I de Kurze Schatten /l e suas respectivas alturas em sons reais no pentagrama inferior.
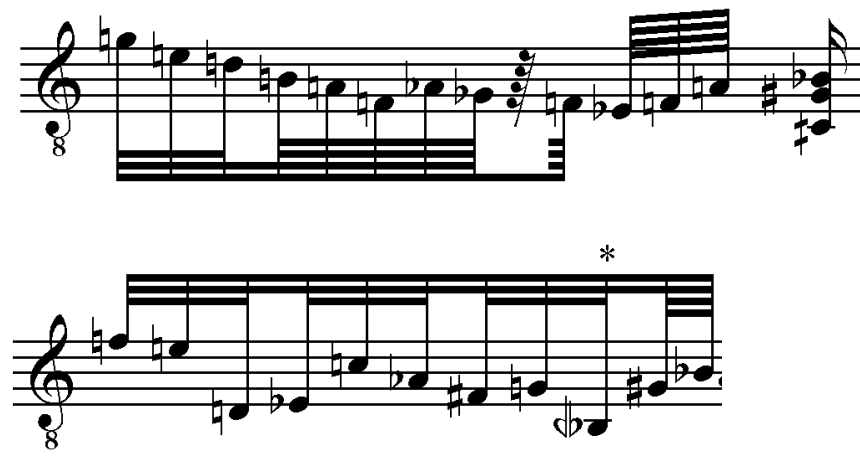

Ex.8- Duas micro-figuras, a superior do compasso 3 e a inferior dos compassos 5 e 6 do Mov.l de Kurze Schatten II.

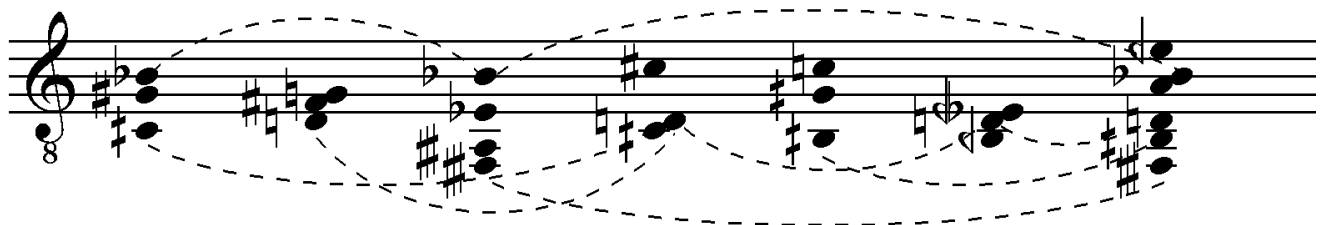

Ex.9- Acordes dos compassos 1 a 8 do Mov.I de Kurze Schatten II. 
Esta espécie de "retorno" fica mais clara quando observamos os acordes desta última seção (Ex. 11), muitos dos quais são quase idênticos aos da primeira, omitindo ou adicionando algumas poucas alturas, ou sendo uma mera transposição, como no caso do último deles.

Por fim gostaria de apontar uma questão interpretativa que o violonista Magnus Andersson expõe em seu texto (ANDERSSON, 1988, p. 128). Segundo Andersson seria preciso executar estas figuras da maneira mais diferenciada possivel, a fim de evitar que elas sejam percebidas apenas como uma superfície global, colocando em evidência um espaço rico em eventos que denotam diversos planos espaciais e temporais.

\section{2 - A música figural na obra de Brian Ferneyhough} Antes de prosseguirmos com a análise do segundo e terceiro movimentos, gostaria de abordar um conceito muito importante dentro da obra de Ferneyhough, o de música figural, que é apresentado em seu artigo Form, Figure and Style (FERNEYHOUGH, 1998, p.21). Neste texto o compositor confronta algumas correntes como a New Simplicity e o New Romanticism, principalmente por tratarem o gesto musical como uma mônada expressiva, carregando diversos significados semânticos específicos, servindo apenas como um veículo para comunicar algo preestabelecido.

Contrariando essa tendência de apostar em uma espécie de revival descontextualizado dos "jogos" dramáticos do passado, através de uma tentativa de criar uma identidade emotiva com o ouvinte, colocando-o em uma escuta extremamente passiva; Ferneyhough busca tratar o gesto não como um símbolo já condicionado historicamente, a fim de liberar toda a força interna presente em cada um de seus subcomponentes, para que estes possam se recombinar livremente e gerar infinitos outros gestos e novas expressões.

Desta maneira o ouvinte necessitaria vivenciar a cada momento a multiplicidade de conexões presentes nos "labirintos" de suas obras, com uma percepção "hiperativa", mudando constantemente seus caminhos e seu foco, sem se prender a um padrão determinado anteriormente.

Para conseguir esta capacidade de interconexão Ferneyhough não se utilizará da variação tradicional e sim de um processo que ele chama de "intensificação figural", que consiste nas transformações realizadas em uma figura periódica, que devido a estas adquire um novo perfil, rompendo assim sua periodicidade. ${ }^{4}$
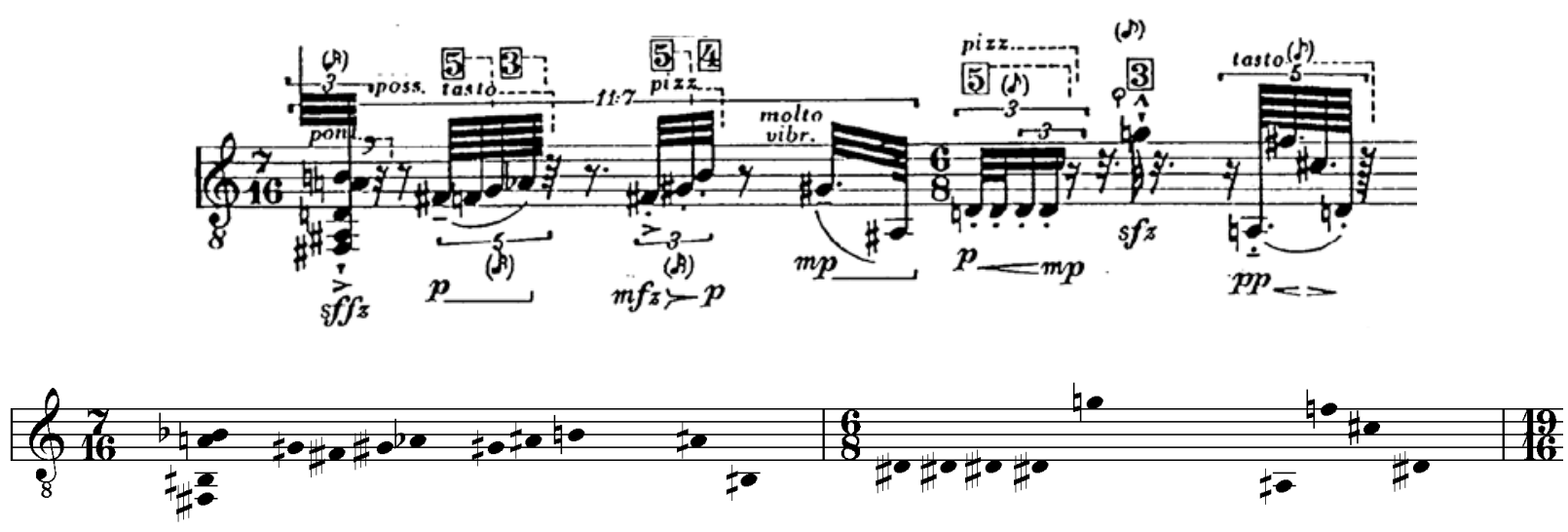

Ex.10- Compassos 13 e 14 da partitura original do Mov.I de Kurze Schatten // com suas respectivas alturas em sons reais no pentagrama inferior.

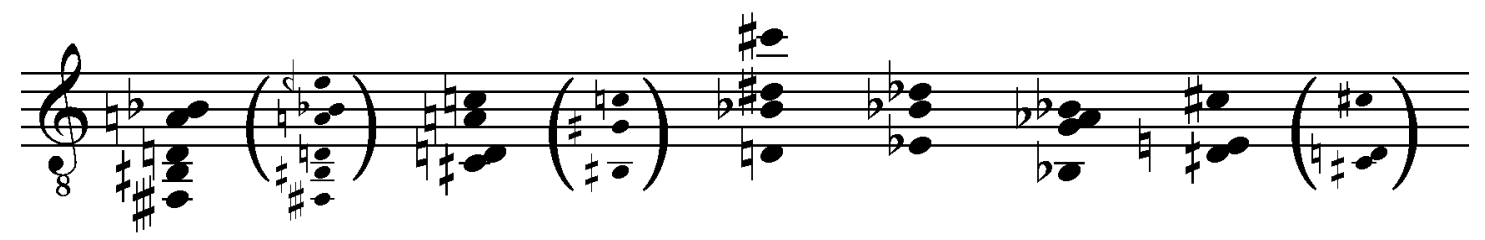

Ex.11- Acordes referentes aos compassos 13 a 20 do Mov.I de Kurze Schatten II, com os semelhantes presentes na primeira sessão mostrados entre parênteses. 


\section{3 - O Segundo movimento de Kurze Schatten II}

\begin{abstract}
0 'tópico' do segundo movimento é a distinção potencial entre tempo de performance e densidade do material percebida. 0 tempo indicado no início é extremamente elevado e decresce através de passos regulares, enquanto que a tendência em termos de densidade de material é o oposto, isto para dizer que, a velocidade dos eventos escritos do início é relativamente baixa, permitindo uma substancial diferenciação polifônica. Conforme a peça progride, os valores rítmicos escritos vão se tornando mais curtos, desta forma comprimindo cada vez mais impulsos dentro do crescente e expansivo quadro temporal de cada seção (FERNEYHOUGH, 1998, p.141).
\end{abstract}

Durante todo o segundo movimento vemos um exemplo bastante claro do processo de intensificação figural, que acontece nas "deformações" que ocorrem na figura apresentada no início. Essa intensificação figural é facilmente percebida devido ao fato desse material encontrar-se em um espaço de contínua expansão, devido à diminuição dos tempos do metrônomo e ao crescente aumento das quantidades de impulsos dentro de cada compasso.

Vemos aqui outro procedimento muito característico da linguagem de Ferneyhough, que é a oposição entre processos de caráter "automático" e "informal". Os processos automáticos seriam aqueles que evidenciam um sistema preestabelecido (como no caso dos procedimentos adotados pelo serialismo). No caso desta peça, eles estão representados pelos grupos de fórmulas de compassos predeterminados e pelos pontos fixos onde ocorrem as mudanças de andamento e apresentação das mesmas alturas escritas.

A peça é composta por seis variações de um grupo de seis fórmulas de compasso, para facilitar nossa análise vamos adotar a seguinte nomenclatura para cada uma delas: $a=5 / 16, b=3 / 16, c=2 / 8, d=1 / 8 \quad e=3 / 8, a^{\prime}=$ $5 / 16$. Então, teremos as seguintes seqüências em cada variação, mostradas no Ex.12.

0 compositor também simula uma espécie de simetria nestas variações, com uma permutação cíclica, ou seja, ele faz com que o primeiro termo se torne o último e o segundo se torne primeiro, mas logo na segunda variação ele inverte a ordem e coloca o primeiro termo como penúltimo, mantendo-o nesta posição (sempre após o primeiro) até o fim, gerando o seguinte esquema de permutações de fórmulas de compasso:

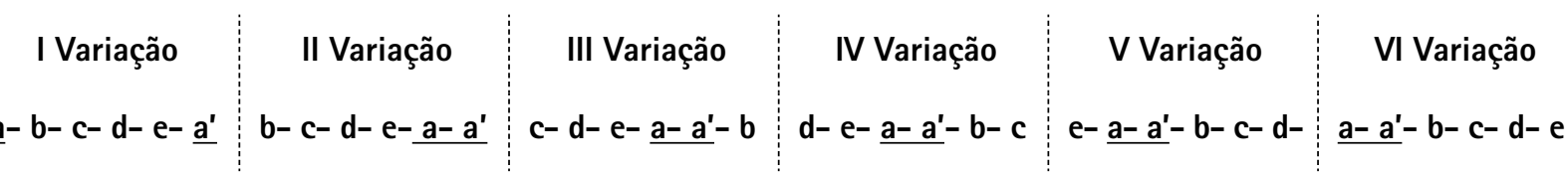

\begin{tabular}{|c|c|}
\hline I variação (C1 a C6): & a- b- c- d- e- a' \\
\hline II variação (C7 a C12): & b- c- d- e- a- a' \\
\hline III variação (C13 a C18): & c- d- e- a- a'- b \\
\hline IV variação (C19 a C24): & d- e- a- a'- b- c \\
\hline V variação (C25 a C30): & e- a- a'- b- c- d \\
\hline VI variação (C31 a C36): & a- a'- b- c- d- e \\
\hline
\end{tabular}

Ex.12 - Tabela com seqüências de fórmulas de compasso de cada variação no Mov.ll de Kurze Schatten II.

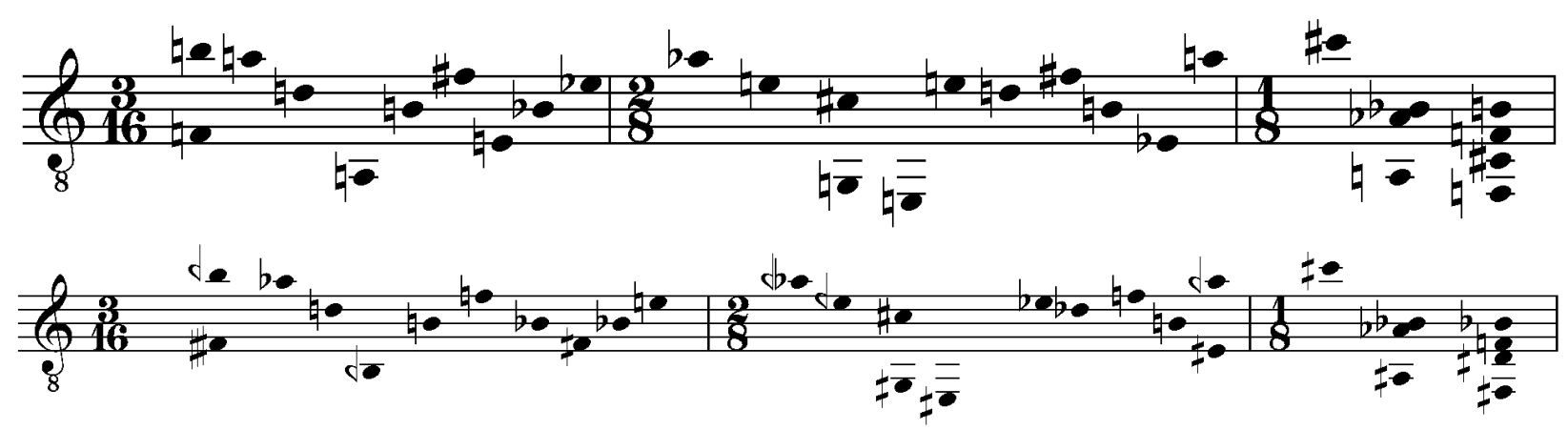

Ex.13- Compassos 1 ao 3 do Mov.Il de Kurze Schatten II: no pentagrama superior temos as alturas escritas e, no inferior, alturas em sons reais. 
Além das variações de seqüências de fórmulas de compasso, no início de cada variação temos uma diminuição no andamento metrônomico, e a presença das mesmas alturas escritas (ver Ex.13 e 14); porém estas sofrem alterações nas oitavas em que são apresentadas e nas cordas onde devem ser executadas, produzindo assim uma espécie de filtragem pela scordatura das mesmas.

Os processos citados acima são aqueles que correspondem ao caráter automático. A idéia de música informal tem origem na releitura que o compositor faz do texto de T. W. ADORNO (1994, p.269), entitulado Vers une musique informelle, e consiste em uma música que estaria livre de qualquer forma abstrata, a priori, obedecendo apenas a sua lógica interna; desta maneira o compositor trataria o material de maneira "construtiva" e localizada, e no caso deste movimento, estaria representado pelas intensificações figurais que ocorrem sem nenhum "esquema" ou plano pré-concebido.

\subsection{0 terceiro movimento de Kurze Schatten II}

0 principio de base é extremamente simples, eu defini uma série de compassos de vários tamanhos diferentes, que após o meio do movimento, com exceção de algumas pequenas irregularidades, vai retrogradado de volta ao seu ponto de início. A maior diferença entre a seqüência original e a métrica retrogradada é que, enquanto que cada compasso alternado na primeira metade contém ou completo silêncio ou uma estrutura interna predeterminada em ressonância tenuto e silêncio, a versão retrogradada inverte esta relação, a fim de que os compassos inicialmente realmente marcados pela música real sejam agora essencialmente silenciosos, e vice versa (FERNEYHOUGH, 1998, p.142- 143).
O terceiro movimento lida com a percepção de vários tipos de fluxo temporal e distribuições do material, dentro de um contexto altamente simétrico, além de ser, dentre todos os demais movimentos, aquele que se utiliza do maior número de técnicas percussivas.

Apresentaremos abaixo (Ex.15 e Ex.16), as duas seqüências de fórmulas de compassos apontadas pelo compositor na citação acima e demostraremos o tipo de acontecimento musical que ocorre dentro de cada uma delas; para isto, dividiremos os acontecimentos musicais nas seguintes categorias: silêncio, música (que indica a presença dos gestos aforísticos que percorrem todo movimento) e tenuto (que consiste na ressonância de um evento realizado em um determinado compasso prolongado até parte do seguinte).

A análise da tabela no Ex.16 acima nos faz constatar que durante a primeira metade da peça existe uma predominância do elemento "música", enquanto que os elementos silêncio e tenuto possuem apenas uma função "pontualística", relação esta que se inverte a partir da metade da peça, onde acontece um domínio do silêncio e os gestos musicais aparecem apenas como aforismas, independentes uns dos outros (Ex.17).

Devido ao grande número de compassos "em branco", onde parece não acontecer nada, e ao andamento que muda a cada intervenção musical, ocorre um grande acúmulo de tensão ao qual o intérprete fica submetido, fazendo com que tenha que realizar uma preparação mental, do próximo evento a ser realizado para que não haja um desvio da energia
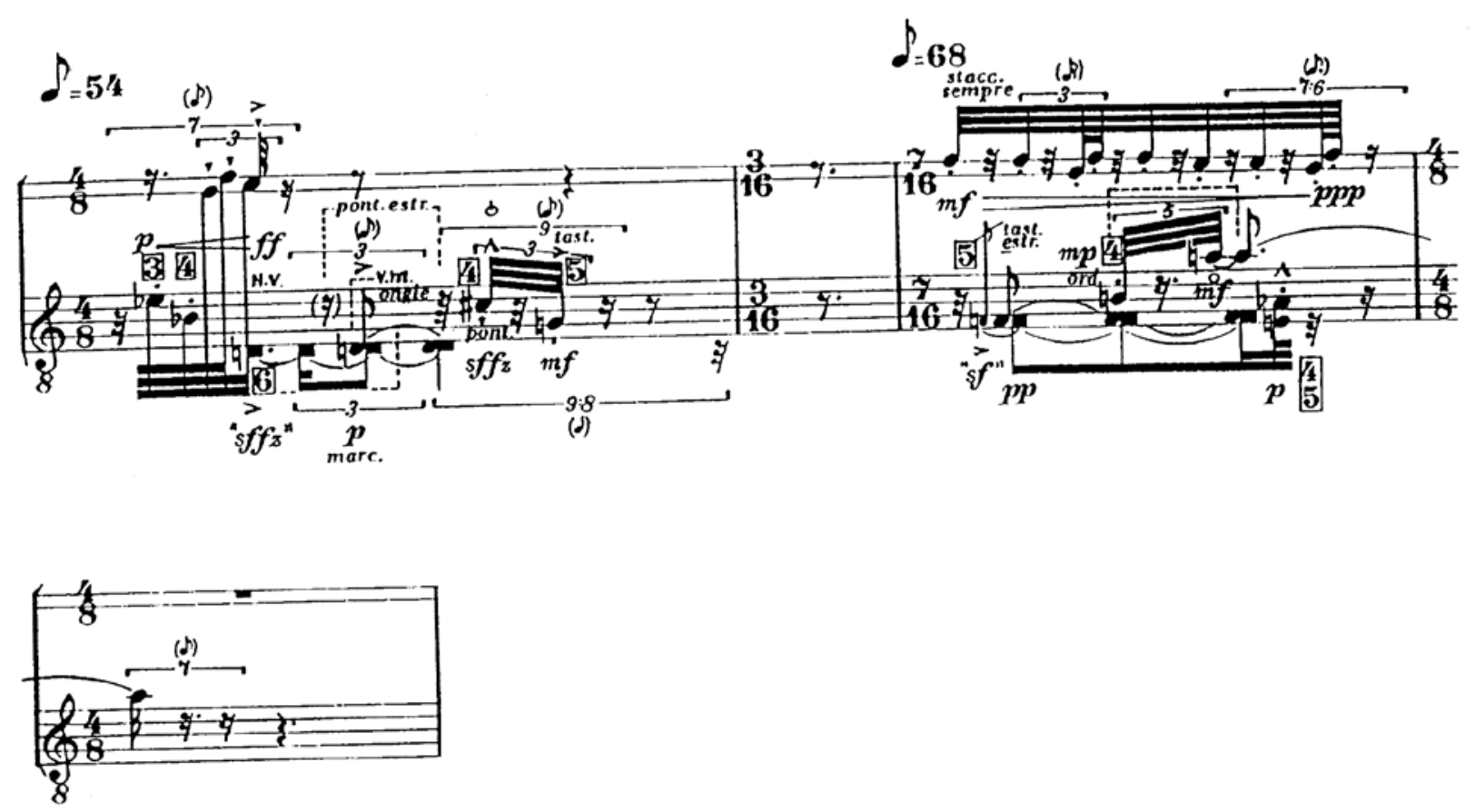

Ex.14- Compassos 7 ao 9 do Mov.II de Kurze Schatten II: no pentagrama superior temos as alturas escritas e, no inferior, alturas em sons reais. 


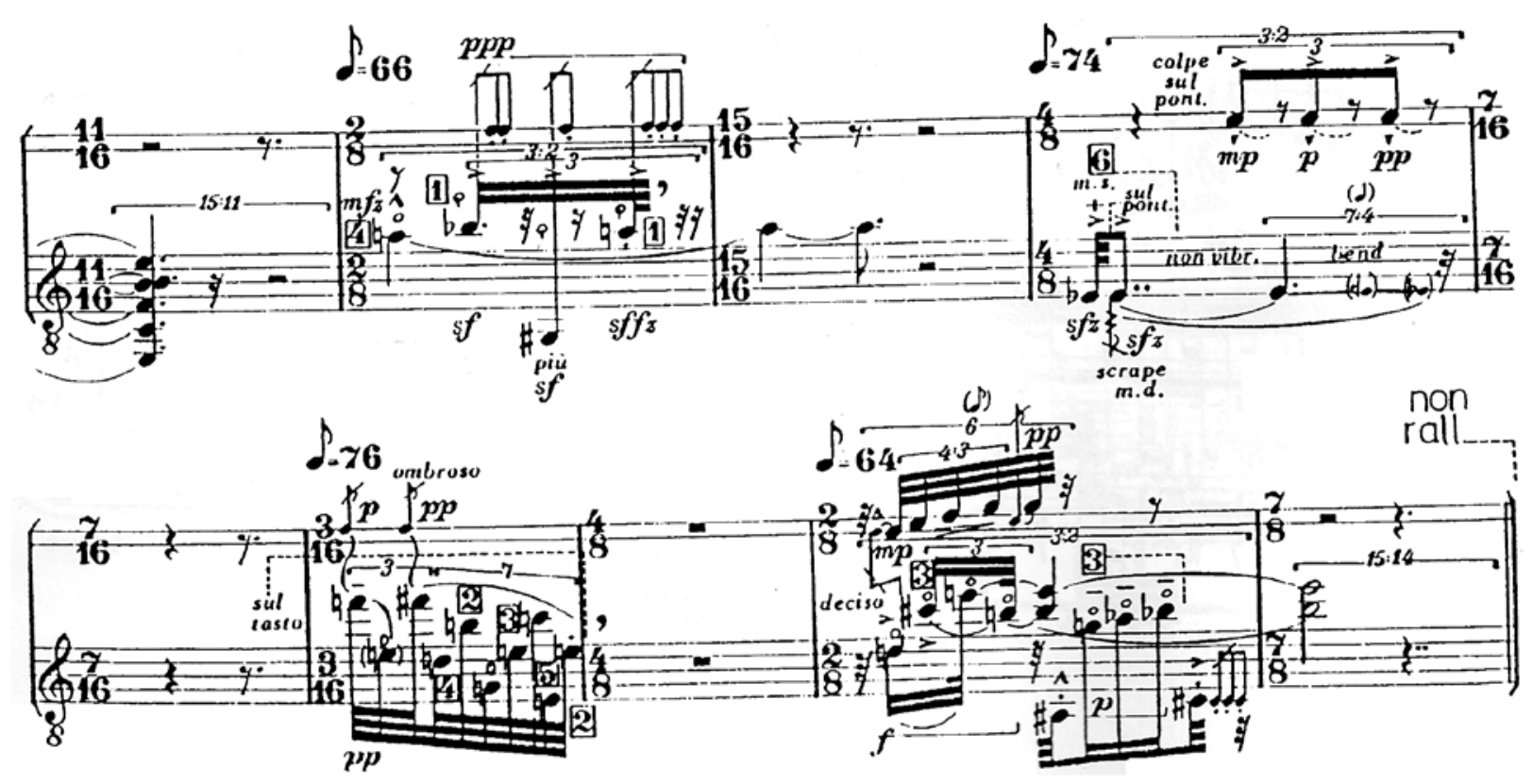

Ex.15 - Compassos 3 a 6 da partitura original do Mov.III de Kurze Schatten II, com ocorrências das seguintes categorias de eventos musicais: música, silêncio, música e tenuto.

Seqüência original:

\begin{tabular}{|c|c|c|c|c|c|c|}
\hline $7 / 8$ & $2 / 8$ & $4 / 8$ & $3 / 16$ & $7 / 16$ & $4 / 8$ & $15 / 16$ \\
\hline Música & Silêncio & Música & Silêncio & Música & Tenuto & Música \\
\hline $2 / 8$ & $11 / 32$ & $3 / 8$ & $13 / 16$ & $4 / 8$ & $15 / 16$ & $2 / 8$ \\
\hline Tenuto & Música & Tenuto & Música & Tenuto & Música & Silêncio \\
\hline
\end{tabular}

Seqüência retrogradada:

\begin{tabular}{|c|c|c|c|c|c|c|}
\hline $2 / 8$ & $15 / 16$ & $4 / 8$ & $13 / 16$ & $3 / 8$ & $11 / 16$ & $2 / 8$ \\
\hline Música & Silêncio & Música & Tenuto & Música & Tenuto & Música \\
\hline $15 / 16$ & $4 / 8$ & $7 / 16$ & $3 / 16$ & $4 / 8$ & $2 / 8$ & $7 / 8$ \\
\hline Tenuto & Música & Silêncio & Música & Silêncio & Música & Tenuto \\
\hline
\end{tabular}

Ex.16 - Tabela com categorias de acontecimentos musicais presentes nas duas seqüências de fórmulas de compassos do Mov.III de Kurze Schatten II. 
necessária para cada intervenção musical. 0 que também podemos notar é que, em sua maioria, estas intervenções musicais são totalmente independentes, tornando o ponto mais interessante deste movimento, o contraste que emerge entre as diferentes figuras aforísticas e entre estas e 0 silêncio, fazendo com que o ouvinte possa até mesmo se lembrar do "conflito" entre densidade do material e fluxo de tempo, apresentado no movimento anterior.

\section{4 - Considerações Finais}

A obra de Brian Ferneyhough, desde a década de 70, tem sido uma referência de extrema importância para os compositores que procuram evitar as diversas tendências facilitadoras da New Simplicitye do New Romanticism. Opondo-se a tentativas de remistificar a expressividade musical por meio de revivals da tradição tonal e modal,
Ferneyhough colocará o ouvinte em um "espaço labiríntico" onde aparentemente os elementos se conectam e desconectam a todo o momento, tendo este que percorrer ativamente seus caminhos e vivenciar suas próprias relações, suas próprias complexidades. Ao intérprete também cabe um papel bastante ativo: este deve criar uma espécie de "contraponto pessoal" com suas obras, pois suas partituras não são apenas "tablaturas", ali se encontra toda a sua história de criação e construção.

0 principal objetivo deste artigo, assim como de toda a minha pesquisa, é criar uma aproximação com a proposta composicional de Brian Ferneyhough, percorrendo os "labirintos" e decifrando as complexidades de seu pensamento e de suas obras.

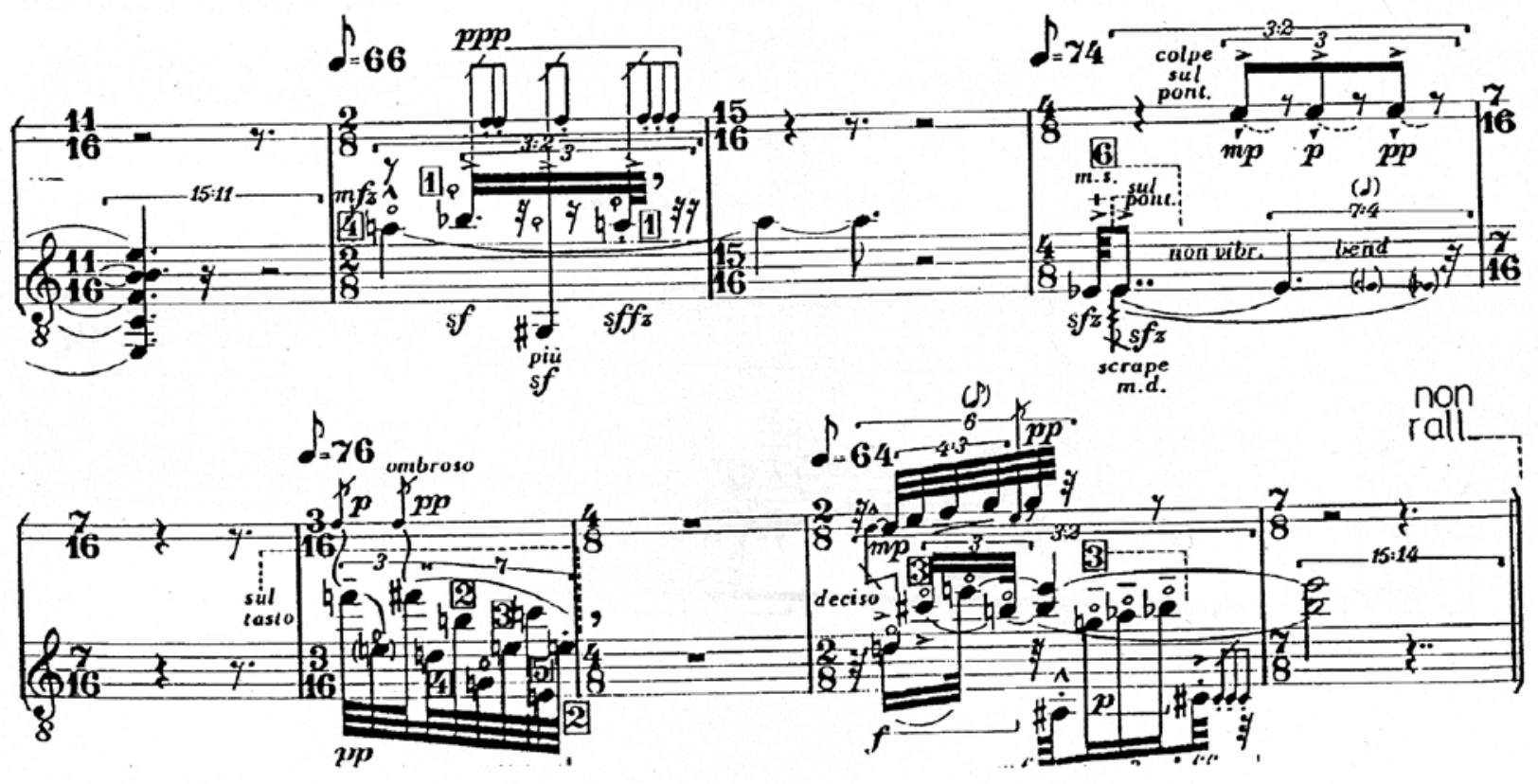

Ex.17- Compassos 20 a 28 da partitura original do Mov.III de Kurze Schatten II, 


\section{Referências}

ADORNO, Theodor W. Quasi una fantasia. Trad: Rodney Livingstone. London/ New York: Verso, 1994.

ANDERSSON, Magnus. "Brian Ferneyhough: Kurze Schatten II considérations d'un interprète". Contrechamps 8 (1988): p.128-138.

BENJAMIN, Walter. Obras Escolhidas II. São Paulo: Brasiliense, 2000.

FERNEYHOUGH, Brian. Collected Writings, ed: James Boros. Amsterdan: Harwood, 1998.

\section{Leitura Recomendada}

FERRAZ, Silvio. Música e Repetição. São Paulo: Educ, 1998.

HIROKI KOZU, Fernando. "A complexidade em Brian Ferneyhough: aspectos de comunicação e inteligibilidade musical". Diss. de mestrado, PUC/SP, 2003.

NICOLAS, François. "Éloge de la complexité". Entretemps 3. (1987): p.56-67.

MELCHIORRE, Alessandro. "Les Labyrinthes de Ferneyhough". Entretemps 3 (1987): p.69-88.

TOOP, Richard. "Prima le parole. (on sketches for Ferneyhough's Carceri d'invezione I-III)". Perspectives of New Music 32, n.1 (1994): p.154-175.

Felipe Merker Castellani, compositor, estudou violão, composição e análise musical com o prof. Paulo de Tarso Salles. Ingressou no curso de composição da Faculdade Santa Marcelina em 2003, onde estuda com Paulo Zuben e Sérgio Kafejian. Realiza um projeto de iniciação científica sobre a obra Kurze Schatten // de Brian Ferneyhough, com bolsa Fapesp e sob orientação de Silvio Ferraz, com quem estuda composição. Teve obras executadas nas XV e XVI Bienais de Música Brasileira Contemporânea, e, II e V Encontro Nacional de Compositores Universitários e no 43 Festival Música Nova..

\section{Notas}

1 As "restrições" são parâmetros preestabelecidos que o compositor define durante o processo de elaboração das obras, porém muitas vezes alguns destes podem ser abandonados durante a composição (que seriam os chamados "erros").

2 As citações de Ferneyhough foram traduzidas pelo Autor; as indicações dos originais estão entre parênteses.

30 sinal $\downarrow$ indica uma nota um quarto de tom mais baixo, assim como $\uparrow$ indica uma nota um quarto de tom mais alto.

4 Este processo pode ser observado na análise do primeiro movimento, apresentada acima, onde as categorias de micro-figuras se transformam muito rapidamente e sem nenhum plano preestabelecido 